\title{
Solving words as anagrams: An issue re-examined
}

\author{
M. S. MAYZNER AND M. E. TRESSELT
}

NEW' YORK UNIVERSITY

\section{Abstract}

The present study compared solution times for word and nonsense anagrams in an attempt to resolve conflicting results obtained in earlier studies. No differences were found in solution times between word and nonsense anagrams and the results were related to an S-R mediational model of anagram problem solving behavior.

Problem

Two recent studies (Beilin \& Horn, 1962; Ekstrand \& Dominowski, 1965) have examined anagram problem solving under conditions in which the anagram was itself a word. This problem had been studied previously by other investigators (Devnich, 1937; Hollingworth, 1935; Nissenson \& Sargent, 1941; Sargent, 1940), however, the results were unclear as to whether word anagrams were or were not more difficult to solve than nonsense anagrams. The studies of Beilin \& Horn (1962) and Ekstrand \& Dominowski (1965) by controlling for the effects of a number of variables, namely, Thorndike-Lorge solution-word frequency. anagram letter order, and anagram and solution-word digram frequency, studied earlier by Mayzner \& Tresselt (1958; 1959, 1962a), found evidence that word anagrams are significantly more difficult to solve than nonsense anagrams.

The present study examines the issue further by employing an experimental design different from those employed by Beilin and Horn and Ekstrand and Dominowski. In the present design rather than comparing the solution times of word and nonsense anagrams for two different samples of problems, a single sample of solution-words is employed. Thus, no problems arise of trying to equate the two solution-word samples on a number of variables, as done by Beilin and Horn and Ekstrand and Dominowski, and a more sensitive test of whether differences in solution time occur between word and nonsense anagrams is perhaps possible.

\section{Method}

Twenty-one Ss selected randomly from introductory psychology classes, and who had notpreviously participated in any anagram studies, were presented with eight test problems. Each problem consisted of a five-letter nonsense anagram to which there were two solutions, with S instructed to find both solutions within a $240 \mathrm{sec}$. time limit. If $\mathrm{S}$ failed to find one or both solutions, he was told the solution or solutions prior to the next problem and given a score of $240 \mathrm{sec}$. for any failed solution. Although solution times for both solution-words were calculated only the solution time for the appropriate solution-word, as shown in Table 1, was used for analysis purposes. All anagrams were typed in caps on 3 by 5 in cards, all Ss were tested individually, and each $\mathrm{S}$ received the eight test problems in a different random order. All solutions were given by $\mathrm{S}$ verbally (i.e., S had no paper or pencil) and solution times were recorded with a stop watch.

The eight test problems or anagrams employed in this study are presented in Table 1 and are as follows: THREA, HOSER, TIDER, etc. Also shown in Table 1 is an equivalent word form of the anagrams, i.e., EARTH, SHORE, TIRED, etc. Since previous studies (Mayzner \& Tresselt, 1959; 1965) have shown that anagram digram frequency totals (i.e., the sum of the frequencies of the four sequential digrams constituting the problem) affect solution time, the anagrams and word forms shown in Table 1 were selected to provide as nearly equal digram frequency totals as possible, as given in the "DF Totals" column. The "DF Totals" were obtained from tables of digram frequencies prepared by Mayzner \& Tresselt (1962b).

Twenty Ss in a previous study (Mayzner \& Tresselt, 1965) had already been presented with the word forms, i.e., EARTH, SHORE, etc., and these results are compared in the present study to the results obtained with the anagram forms, i.e., THREA, HOSER, etc. Thus, in this study the solution times to the solutionwords HEART, HORSE, etc., given under the "Solution Words" column in Table 1, have been obtained from two different groups of Ss, one group presented with the anagram forms and the other group presented with the word forms, but both groups required to find the same solution-word. Therefore, any differences which exist in solution times may most probably be attributed to the characteristics of the anagram and not to possible uncontrolled factors present in the solution-words, which may have occurred in the Beilin and Horn and Ekstrand and Dominowski studies, where two different groups of solution-words were employed.

\section{Results and Discussion}

Median solution times for the eight test problems are presented in Table 1 . The times shown under the column labelled "Old" are from the earlier study by Mayzner \& Tresselt (1965) in which Ss were presented with the word form of the anagram, while the times shown under the column labelled "New" are from the present study in which Ss were presented with the nonsense form of the anagram. As may be seen, five of the eight problems yield longer solution times for the nonsense anagrams, while only three problems yield longer solution times for the word anagrams. These results are in sharp contrast to those obtained by 
TABLE I

Anagrams, Solution-Words, Anagram Digram Frequency Totals, and Median Solution Times for the Eight Test Problems

\begin{tabular}{ccccc} 
& & & \multicolumn{2}{c}{ Median Solution Times } \\
\cline { 3 - 5 } DF Totals & Anagrams & Solution Words & Old & New \\
\hline 5674 & THREA & HEART & & 56.0 \\
5436 & EARTH & HEART & 14.5 & \\
2622 & HOSER & HORSE & 10.5 & 142.0 \\
2766 & SHORE & HORSE & 10.0 \\
2201 & TIDER & TRIED & & 120.0 \\
2430 & TIRED & TRIED & 25.0 & \\
2299 & TWORE & WROTE & & 102.0 \\
2328 & TOWER & WROTE & 81.0 & \\
1493 & RHACM & CHARM & & 23.0 \\
1239 & MARCH & CHARM & 12.5 & \\
1095 & DORBA & BOARD & & 16.0 \\
1039 & BROAD & BOARD & 61.0 & \\
661 & GNITH & THING & & 4.0 \\
821 & NIGHT & THING & 50.0 & \\
1055 & GORWN & WRONG & & 18.0 \\
1103 & GROWN & WRONG & 24.0 & \\
\hline
\end{tabular}

Beilin and Horn and Ekstrand and Dominowski, who would have predicted the word anagrams to be more difficult than the nonsense anagrams. In fact, using the Sign Test (Siegel, 1956), only one problem out of eight could show a faster solution time for the word anagram form in contrast to the nonsense anagram form $(p<.035)$ if the results were to support the Beilin and Horn and Ekstrand and Dominowski position, while our results show a five out of eight split.

In contrast to Beilin and Horn and Ekstrand and Dominowski, the results of the present study show an almost pure chance split, five out of eight versus a pure chance split of four and four, between the solution times associated with the word and nonsense anagrams. Such a chance split, as was found in the present study, would be in line with the S-R mediational model of Kendler (1961) that the present authors (Mayzner \& Tresselt, 1958, 1959, 1962a, 1963, 1965; Mayzner, Tresselt, \& Helbock, 1964; Tresselt \& Mayzner, 1965) have been employing to conceptualize anagram problem solving behavior, since all relevent model variables have been equated, yielding a prediction of a chance split.

The discrepancy in results, however, between the present study and those of Beilin and Horn and Ekstrand and Dominowski, still needs to be resolved. First, in connection with the Beilin and Horn study, one could raise a serious question as to whether they are actually studying anagram problem solving, since they changed the typical anagram task with free movement of all letters to a very special type of highly simplified and highly restricted two-letter exchange task, which may be quite inappropriate to the issue in question. Second, Ekstrand and Dominowski used two different solution-word samples, in which as yet unidentified and uncontrolled variables may have been operating. Finally, our present S-R model may need to incorporate the possible interfering effects generated by word anagrams, above and beyond letter transitional effects. More specifically, word anagrams or even nonsense anagrams may produce interfering mediational responses, representing word or word-like associations to the anagram stimulus. This possibility might be tested by prior scaling of word and nonsense anagrams in a free association test and then determining whether word or nonsense anagrams that produce more or faster free associations are more difficult to solve than those that do not, all other factors being equal, because of greater mediational interference effects.

\section{References}

Beilin, H., \& Horn, R. Transition probability effects in anagram problem solving J. exp. Psychol., 1962, 63, 514-518.

Devnich, G. E. Words as "Gestalten." J. exp. Psychol., 1937, $20,297-300$.

Ekstrand, B .R., \& Dominowski, R. L. Solving words as anagrams. Psychon. Sci., 1965, 2, 239-240

Hollingworth, H. L. The conditions of verbal configuration. $J$ exp. Psychol., 1935, 18, 299-306

Kendler, H. H. Problems in problem solving research. In Current trends in psychological theory: $A$ bicentennial program. Pittsburgh: University Pittsburgh Press, 1961.

Mayzner, M. S., \& Tresselt, M. E. Anagram solution times: A function of letter order and word frequency. J. exp. Psychol., $1958,56,376-379$

Mayzner, M. S., \& Tresselt. M. E. Anagram solution times: A function of transition probabilities. J. Psychol., 1959, 47, 117-125.

Mayzner, M. S., \& Tresselt, M. E. Anagram solution times: A function of word transition probabilities. J. exp. Psychol., $1962 \mathrm{a}, 63,510-513$.

Mayzner, M. S., \& Tresselt, M. E. Tables of digram and singleletter frequency counts by word-length and letter-position for a sample of 20,000 words. Mimeographed copy, New York University Library, 1962b

Mayzner, M. S., \& Tresselt, M. E. Anagram solution times: A function of word length and letter position variables. .J. Psychol., $1963,55,469-475$

Mayzner, M. S., \& Tresselt, M. E. Anagram solution times: A function of multiple-solution anagrams. J. exp. Psychol., 1965, in press.

Mayzner, M. S., Tresselt, M. E., \& Helbock, H. An exploratory study of mediational responses in anagram problem solving. J. Psychol., 1964, 57, 263-274.

Nissenson, M., \& Sargent, S. S. Words as configurations. J. exp. Psychol., 1941, 28, 85-89.

Sargent, S. S. Thinking processes at various levels of difficulty. Arch. Psychol., N. Y., 1940, No. 249

Siegel, S. Nonparametric statistics for the behavioral sciences. New York: McGraw-Hill, 1956.

Tresselt, M. E. \& Mayzner, M. S. Anagram solution times: A function of individual differences in stored digram frequencies. J. exp. Psychol., 1965, in press. 